\title{
Pemakaian Ventilator Frekuensi Tinggi pada Bayi Asfiksia Berat
}

\author{
Isra Firmansyah, Munar Lubis
}

\begin{abstract}
Asfiksia berat merupakan keadaan gawat darurat bayi baru lahir yang membutuhkan bantuan ventilasi mekanik segera. Ventilator merupakan alat bantu pernapasan yang dapat digunakan untuk memperbaiki ventilasi alveolar, pembuangan $\mathrm{CO} 2$, serta oksigenasi jaringan yang adekuat. Jenis ventilator mekanik yang sering digunakan, yaitu ventilator mekanik konvensional dan ventilator frekuensi tinggi. Ventilator mekanik konvensional mulai ditinggalkan karena efek samping yang ditimbulkannya. Kini telah dikembangkan penggunaan ventilator frekuensi tinggi dengan risiko barotrauma yang lebih rendah karena tekanan, volume dan frekuensi oksigen yang diberikan dapat diatur. Pada makalah ini dibahas pemakaian ventilator frekuensi tinggi pada bayi asfiksia berat.
\end{abstract}

Kata kunci : asfiksia berat, ventilator frekuensi tinggi

$\not{A}$ sfiksia adalah suatu keadaan dengan karakteristik hipoksia yang progresif, hiperkapnia, dan asidosis. ${ }^{1,2}$ Asfiksia pada masa perinatal akan menyebabkan terjadinya penurunan kadar oksigen, saturasi oksigen dan perfusi darah ke jaringan, sehingga menimbulkan iskemia pada organ yang sensitif terhadap penurunan oksigen., ${ }^{2,3}$ Antisipasi dan penanganan dini bayi asfiksia dapat membantu menghindarkan bayi tersebut dari kecacatan dan dampak merugikan pada tumbuh kembang di kemudian hari. Selain bayi kurang bulan, bayi dengan asfiksia berat masih menempati tingkat kematian dan kesakitan yang tinggi di negara berkembang. Demikian pula dampak jangka panjang masih merupakan problem baik bagi keluarga maupun negara $^{1,4,5}$

\footnotetext{
Alamat Korespondensi:

Dr. Munar Lubis, Sp.A(K).

Kepala Unit PGD / PICU Bagian Ilmu Kesehatan Anak. FK-USU/RS

H Adam Malik, Medan. Jl. Bunga Lau no. 17, Medan 20136.

Telepon: 061-836 1721. Fax. 061-836 1721.

dr. Isra Firmansyah

Bagian Ilmu Kesehatan Anak FK - USU / RSHAM Jl. Bunga Lau no. 17 Medan.

Telepon : (061) 8361721, Fax. (061) 8361721
}

Beberapa keadaan yang dihubungkan dengan terjadinya asfiksia pada bayi baru lahir, antara lain respiratory distress syndrome (RDS), pulmonary air leak, fistula bronkopleural, hipertensi pulmonal persisten, sindrom aspirasi mekonium, pneumonia neonatal, hipoplasi pulmonal, hernia diafragmatika, malformasi kistik paru dan lain-lain., ${ }^{2,3}$ The American Academy of Pediatrics dan The American College of Obstetricians and Gynecologists menyatakan bahwa neonatus yang mengalami asfiksia berat saat lahir, dengan asidosis metabolik $(\mathrm{pH}<7)$ dan nilai apgar menetap 0 sampai 3 selama lebih dari lima menit, akan berlanjut menjadi ensefalopati hipoksik. Maka untuk mencegah terjadinya hal tersebut perlu segera dilakukan bantuan ventilasi. ${ }^{4,6,7}$

Bantuan ventilasi didefinisikan sebagai usaha untuk memindahkan udara ke dalam dan ke luar paru dengan menggunakan suatu alat yang dihubungkan langsung kepada pasien. Peralatan yang digunakan dapat bermacam-macam bentuknya, resuscitation bag atau ventilator. Pada neonatus, bantuan ventilasi biasanya diberikan sementara untuk membantu fungsi paru sampai pasien dapat bernapas secara adekuat tanpa pertolongan. Bantuan ventilasi ini akan memperbaiki ventilasi alveolar, pembuangan $\mathrm{CO}_{2}$, oksigenasi yang adekuat serta menurunkan kerja pernapasan..$^{5-7}$ 


\section{Patologi bayi asfiksia berat}

Bayi mempunyai kebutuhan oksigen yang lebih tinggi dibandingkan orang dewasa karena metabolisme pada bayi lebih tinggi. Konsumsi oksigen pada bayi 6-8 $\mathrm{ml} / \mathrm{kg}$ per menit dibandingkan dengan 3-4 $\mathrm{ml} / \mathrm{kg}$ per menit pada orang dewasa. Oleh karena itu bila terjadi henti napas atau ventilasi alveolar yang kurang, hipoksemia lebih cepat terjadi pada anak. ${ }^{1,3,7}$ Penyakit yang berlanjut ke distres pernapasan atau gagal napas dapat menyebabkan hipoksemia, melalui beberapa mekanisme yaitu penurunan compliance komplians paru dan atau peningkatan tahanan udara yang akan meningkatkan usaha napas dan kebutuhan oksigen, gangguan pertukaran oksigen, $\mathrm{CO}_{2}$, ketidaksesuaian ventilasi dan perfusi dengan akibat pirau aliran darah paru sehingga terjadi hipoksemia. ${ }^{1,7,8}$ Pada keadaan asfiksia berat terjadi perubahan yang sangat dramatis, $\mathrm{pH}$ darah turun dari 7.3 menjadi 6.8 pada menit ke 10, $\mathrm{paCO}_{2}$ naik dari $45 \mathrm{mmHg}$ menjadi $150 \mathrm{mmHg}$, $\mathrm{paO} 2$ turun, asam laktat sebagai refleksi metabolisme anaerob dan penumpukan asam akan sangat meningkat, sehingga akhirnya terjadi depresi otak yang hebat. Hipoksia dapat terjadi secara terus menerus atau intermiten. Kelangsungan hidup neonatus akan menurun secara bermakna sesuai dengan konsentrasi oksigen dan lamanya hipoksia., ${ }^{2,9}$

\section{Pemakaian ventilator frekuensi tinggi}

Apabila fungsi paru untuk melaksanakan pembebasan $\mathrm{CO}_{2}$ atau pengambilan $\mathrm{O}_{2}$ dari atmosfir tidak cukup, maka dapat dipertimbangkan pemakaian ventilator mekanik. Tidak semua kegagalan pernapasan merupakan indikasi untuk penggunaan ventilator. Tetapi dapat diramalkan bahwa tanpa penggunaan alat ini maka keadaan gagalnya pernapasan akan semakin berat dan dapat berakhir dengan kematian. ${ }^{1,6,9}$ Walaupun demikian penggunaan ventilator mekanik juga mempunyai risiko yaitu terjadinya barotrauma serta displasia bronkopulmonal. ${ }^{3,10}$

Ventilator dibagi dua jenis, yaitu ventilator tekanan negatif dan ventilator tekanan positif. Ventilator tekanan negatif membuat lingkungan negatif disekeliling dada sehingga mengakibatkan udara masuk ke dalam paru. Contohnya adalah tank respirator dan curais respirator. Ventilator tekanan positif membuat tekanan positif dalam saluran napas sehingga udara masuk ke dalam paru. Terdapat dua bentuk ventilator tekanan positif, yaitu ventilator mekanik konvensional yang mampu memberi udara dengan volume besar, tekanan tinggi dan frekuensi rendah. Yang lain adalah ventilator frekuensi tinggi yang mampu memberikan aliran udara dengan volume kecil, tekanan rendah, dan frekuensi tinggi. ${ }^{6,11-13}$ Ventilator mekanik konvensional mempunyai 3 tipe yaitu (1) tipe pressure cycle, pada tipe ini udara mengalir ke dalam paru dengan tekanan tertentu dan kemudian titik waktu pengaliran udara ini akan terhenti setelah mencapai tekanan tertentu dan kemudian pasien mulai ekspirasi kembali. Oleh karena tekanan telah diatur maka jumlah udara yang masuk selama inspirasi tergantung pada tahanan dan daya kembang paru. Ventilator ini mempunyai bentuk yang sederhana, mudah digunakan, tidak membutuhkan ruang atau tempat yang luas, dapat diletakkan di samping tempat tidur pasien dan harganya lebih murah dibandingkan dengan tipe volume. (2) tipe time cycle, pada tipe ini aliran inspirasi gas diubah menjadi inspiratory time. Volume tidak diatur oleh aliran dan waktu inspirasi.(3) tipe volume cycle, volume udara diatur sampai tekanan tertentu dan didasarkan pada compliance dan resistensi paru. ${ }^{11,12}$ Komplikasi penggunaan ventilator mekanik konvensional meliputi trauma saluran napas, chronic lung injury, air leaks syndrome, retinopathy of prematurity, infeksi, perdarahan intra kranial dan lain-lain. ${ }^{4,11}$

Ventilator frekuensi tinggi merupakan variasi dari ventilator mekanik, yaitu suatu alat yang dirancang untuk memberikan ventilasi dengan cepat, menggunakan volume tidal yang kecil dan mengurangi ruang rugi. Teknik ini lebih baik dari alat ventilator mekanik konvensional, yaitu dapat mempertahankan volume semenit yang cukup dengan tekanan saluran pernapasan proksimal yang lebih rendah, hal tersebut tidak dapat dilakukan dengan menggunakan ventilator mekanik konvensional. Untuk penanganan kolaps paru dengan tekanan saluran pernapasan yang tinggi dapat digunakan ventilator frekuensi tinggi. ${ }^{7,14}$ Alat ini juga mempunyai kemampuan untuk memberikan ventilasi yang cukup walaupun volume tidal diturunkan sehingga dapat menurunkan risiko barotrauma. Angka kecepatan selama diberikan ventilator frekuensi tinggi sering dinyatakan dalam hertz $(\mathrm{Hz})$. Kecepatan 1 hertz (1 siklus/detik) sebanding dengan 60 denyut per menit. ${ }^{7}$

Beberapa keadaan pada bayi asfiksia berat yang memerlukan bantuan ventilator frekuensi tinggi, yaitu (1) Gagal napas, (2) Emfisema intersisial pulmonal. 
Beberapa pusat penelitian menggunakan ventilator frekuensi tinggi untuk penanganan stadium awal yang gagal atau tidak respon terhadap ventilator mekanik konvensional, (3) Fistula bronkopleural berat, (4) Hipertensi pulmonal yang berhubungan atau tidak dengan penyakit parenkim paru (misalnya aspirasi mekonium, pneumonia, hipoplastik paru dan hernia diafragmatika) yang akan mengakibatkan gagal napas dan mempunyai angka mortalitas yang tinggi. Dari beberapa penelitian didapatkan bahwa penggunaan awal ventilator frekuensi tinggi dapat menurunkan 25 - 45 \% kematian, (5) Penyakit membran hialin, (6) Respiratory distress syndrome, (7) Malformasi kistik paru, (8) Pulmonary air leak. ${ }^{10,15}$

\section{Jenis ventilator frekuensi tinggi yang digunakan pada bayi asfiksia berat}

Terdapat tiga tipe ventilator frekuensi tinggi. Froese dan Bryan membuat tiga klasifikasi berdasarkan pada sifat pernapasan, yaitu (1) High frequency positive pressure ventilator (HFPPV), (2) High frequency jet ventilator (HFJV) dan (3) High frequency oscillatory ventilator (HFOV). ${ }^{6,7,15}$

\section{High Frequency Positive Pressure Ventilator (HFPPV)}

Tipe HFPPV merupakan adaptasi dari ventilator mekanik konvensional yang bekerja meningkatkan pernapasan dengan kecepatan tinggi, yaitu 60 sampai 150 kali permenit. Alat ini pertama sekali diperkenalkan di Swedia oleh Sjostrand yang melakukan penelitian terhadap 2000 orang dewasa dan anak-anak selama menjalani pembedahan dan 32 neonatus yang menderita sindrom gagal napas. Ternyata penggunaan alat ini dapat membantu respirasi dengan adekuat. Pada tahun 1980, Bland dan kawan-kawan melaporkan adanya perbaikan pada 24 bayi yang menderita sindrom gawat napas SGN setelah diberikan ventilator dengan kecepatan pernapasan berkisar 60 sampai 110 kali permenit. Sejak tahun 1980 penggunaan HPPV pada bagian perawatan intensif neonatus menjadi populer di seluruh dunia. Ada dua jenis HPPV yang sering digunakan, yaitu Infrasonic Infant Star ventilator dan Volumetric Diffusive Respirator. ${ }^{7,8,16}$

Ventilator HFPPV mempunyai karakteristik yang hampir sama dengan High Frequency Oscillatory Ventilator (HFOV) dan High Frequency Jet Ventilator $(H F J V)$, alat ini dijalankan dengan frekuensi yang sama seperti HFOV tetapi pasien berada dalam keadaan ekspirasi pasif dan udara yang berlebihan dapat dikeluarkan melalui selang endotrakea. Ventilator HFPPV yang sering digunakan dan mendapat persetujuan dari Food and Drug Administration (FDA) adalah jenis Infrasonic Infant Star Ventilator. Ventilator ini mempunyai katup pneumatik yang dikontrol oleh mikroprosesor yang dapat mengubah aliran udara inspirasi untuk mengawali terjadinya peak inspiratory pressure (pips). ${ }^{10,19}$ Penggunaan HFPPV biasanya dikombinasikan dengan ventilator mekanik konvensional (VMK). Kecepatan, positive end expiratory pressure (PEEP) dan positive airway pressure $(P A P)$ diatur oleh VMK. ${ }^{7,10,17}$

\section{High Frequency Jet Ventilator ( HFJV)}

Ventilator HFJV adalah ventilator mekanik yang dapat menghantarkan udara dengan kecepatan tinggi ke dalam saluran pernapasan atas secara langsung melalui selang endotrakeal atau jet injector. Jet ventilator dapat mempertahankan oksigenasi dan ventilasi. Ventilator ini mempunyai volume kompresibel dan bekerja secara efektif dengan frekuensi 150 atau 240 sampai dengan 600 kali per menit. Selama alat ini bekerja pasien berada dalam keadaan ekspirasi pasif. Karena penghantaran udara dilakukan dengan kecepatan tinggi, maka sangat sulit untuk dilakukan monitor tekanan udara di dalam saluran pernapasan. Untuk mengatasi hal ini maka dibuatlah suatu alat yaitu triple lumen hi-lo-jet Endotracheal tube untuk memonitor tekanan udara dalam lumen selang endotrakeal. Alat ini ditempatkan di bagian distal kira-kira $7 \mathrm{~cm}$ dari ujung selang endotrakeal. ${ }^{6,18,19}$ Jet ventilator ini telah dicoba pada bayi dan anak-anak. Jenis yang sering digunakan dan telah mendapat persetujuan oleh FDA adalah jenis bunnell life pulse jet ventilator buatan Amerika yang di disain khusus untuk digunakan bayi. ${ }^{7}, 15,16$

\section{High Frequency Oscillatory Ventilator (HFOV)}

Ventilator HFOV adalah modifikasi ventilator mekanik yang menggunakan piston sebagai pompa atau diafragma getar. Alat ini dapat bekerja dengan frekuensi 600 sampai 
dengan 900 kali per menit ( 10 sampai $15 \mathrm{~Hz}$ ). Selama alat ini bekerja, inspirasi dan ekspirasi tetap aktif (tekanan saluran napas proksimal adalah negatif selama ekspirasi). Osilator dapat menghantarkan udara segar tanpa terputus ke dalam saluran pernapasan. ${ }^{15,17}$ Tekanan osilasi dalam saluran pernapasan menghasilkan volume tidal yang rendah dan akan mempertahankan volume paru. 9,15,16 Pengalaman klinik pertama penggunaan HFOV adalah pada bayi prematur yang menderita penyakit membran hialin yang gagal dengan penggunaan VMK dan berlanjut menjadi penyakit chronic lung disease. ${ }^{9,10}$ Jenis yang sering digunakan dan telah direkomendasikan oleh FDA adalah sensor medics 3100 A oscillator. Alat ini menggunakan sebuah piston osilasi dan tidak dihubungkan dengan ventilator mekanik konvensional. Parameter yang diukur adalah frekuensi dan tekanan saluran napas rata-rata. ${ }^{6,9,10}$ Beberapa penelitian prospektif telah dilakukan untuk membandingkan HFOV dengan VMK, antara lain satu studi di Amerika Utara menemukan penurunan insiden kematian, frekuensi serta beratnya penyakit paru kronik pada bayi usia 28 hari dengan berat badan lahir 750 sampai 1250 g. Selanjutnya penelitian kedua yang dilakukan pada tahun 1988 sampai 1990 mendapatkan hasil penurunan risiko terjadinya air leak syndrome. ${ }^{4,6,15}$ Clarck dan kawankawan menemukan penurunan insiden displasia bronkopulmonal pada kasus yang diberikan HFOV. Lamanya pemakaian HFOV yang pernah dilaporkan berkisar antara 7 sampai 20 hari. ${ }^{4,10}$

\section{Komplikasi penggunaan ventilator frekuensi tinggi}

Komplikasi utama penggunaan ventilator frekuensi tinggi adalah terperangkapnya udara dalam paru. Tetapi hal ini dapat dicegah dengan memonitor gas darah serta foto toraks secara serial. Apabila dijumpai tandatanda peningkatan tekanan intra toraks serta adanya overinflasi, maka tekanan dapat diturunkan. ${ }^{1,4,7}$

\section{Penghentian ventilator frekuensi tinggi}

Jika fungsi hemodinamik telah berjalan baik, oksigenasi telah cukup adekuat, pasien dalam keadaan sadar dan ventilator siap dilepaskan, maka dapat dilakukan penghentian atau pelepasan ventilator. Adapun syaratsyarat penghentian ventilator adalah (1) Jika $\mathrm{paO}_{2}$ telah normal dan gambaran foto toraks tidak memperlihatkan gambaran hiperinflasi atau atelektasis paru, (2) $\mathrm{Bila}_{\mathrm{FiO}}$ $60 \%$, PEEP dihentikan, (3) Jika $\mathrm{paCO}_{2}$ telah turun sampai dengan normal ( $\mathrm{paCO}_{2}<40 \mathrm{mmHg}$ ), amplitudo dihentikan, (4) Ketika amplitudo mencapai batas terendah $(10 \mathrm{ml})$, dapat dimulai pernapasan biasa. ${ }^{4,6,10}$

Ada beberapa hal yang perlu diperhatikan atau dimonitor pada neonatus asfiksia berat selama pemakaian ventilator frekuensi tinggi, yaitu ukuran dan posisi pemasangan selang endotrakeal, tanda klinis (warna kulit, frekuensi pernapasan, pola pernapasan, adanya retraksi atau tidak, kesesuaian gerakan dada dan perut), analisa gas darah serta foto toraks untuk menilai adanya pulmonary air leak, atelektasis dan lain-lain. Selain itu juga dimonitor $\mathrm{FiO}_{2}, P I P, P E E P$, paw, rate, flow rate, I : E 1:2 dan volume tidal. ${ }^{10,19}$

Selama melakukan penghentian pemakaian ventilator frekuensi tinggi perlu dilakukan monitoring elektrolit, kalsium, glukosa, ureum, dan kreatinin. Karena gangguan metabolik akan mempengaruhi proses penghentian ventilator tersebut, pasien dipuasakan selama 4 jam sebelum ekstubasi atau makanan diberikan melalui selang nasogastrik., ${ }^{2,9,10}$

\section{Kesimpulan}

Kadang kala penanganan gagal napas pada neonatus dengan asfiksia berat tidak berhasil dengan menggunakan ventilator mekanik konvensional. Untuk itu dianjurkan menggunakan ventilator frekuensi tinggi yang mempunyai kelebihan dibandingkan dengan ventilator mekanik konvensional. Yaitu dapat menghantarkan gas atau udara secara langsung ke dalam saluran pernapasan dengan kecepatan tinggi sehingga pertukaran udara paru menjadi optimal. Selain itu efek samping barotrauma serta displasia bronkopulmonal lebih rendah dibandingkan dengan ventilator mekanik konvensional.

Selain mempunyai beberapa keuntungan, ventilator frekuensi tinggi juga mempunyai efek samping yang tidak ringan pula, maka sebaiknya penggunaan ventilator frekuensi tinggi dilakukan dengan bantuan tenaga ahli yang telah terlatih dan dididik secara khusus untuk itu.

\section{Daftar Pustaka}

1. Karlowicz MG, Karotkin EH, Goldsmith JP. Rescucitation. Dalam: Goldsmith JP, Karotkin EH, 
penyunting. Assisted ventilation of the neonate. Edisi ke- 3. Philadelphia: Saunders; 1996. h. 83-6.

2. Deep R, Kuhlman K. Identification and management of the fetus at risk for acidosis. Dalam: Spitzer AR, penyunting. Intensive care of the fetus and neonate. USA: Mosby; 1996. h. 105-7.

3. Carey BE. Neurologic assessment. Dalam: Tappero EP, Honeyfield ME, penyunting. Physical assessment of the newborn. Edisi ke-2. Petaluma : Nicu ink; 1996. h. 150-1.

4. Pusponegoro TS, Chair I, Wiknjosastro GH. Buku panduan resusitasi neonatus. Jakarta: Perinasia;1998. h. 4-15.

5. UKK pediatri gawat darurat. Kumpulan materi pelatihan resusitasi pediatrik tahap lanjut, , IDAI 2001; 2-10.

6. Golden SM, Peters DY. Delivery room care. Dalam: Merenstein GB, Gardner SL, penyunting. Handbook of neonatal intensive care. Edisi ke- 3. USA: Mosby; 1993. h. 55-6.

7. Epstein MF. Resuscitation. Dalam: Avery ME, Taeusch W. Scaffer's,penyunting. Diseases of the newborn. Edisi ke- 5. Philadelphia:Saunders;1984. h. 100-6.

8. Kercsmar CM. The respiratory system. Dalam: Behrman RE, Kliegman RM, penyunting. Nelson essentials of pediatrics. Edisi ke- 2. Philadelphia: Saunders; 1994. h. 433-43.

9. Goldsmith JP, Karotkin EH. Introduction to assisted ventilation. Dalam: Goldsmith JP, Karotkin EH, penyunting. Assisted ventilation of the neonate. Edisi ke- 3. Philadelphia: Saunders; 1996. h. 1-17.

10. Gomella TL, Cunningham MD, Eyal EG. Neonatology: Management, procedures,on-call problems, diseases and drugs. Edisi ke-3. USA: Lange; 1994. h.7-16.
11. Harris TR, Wood BR. Physiologic principle. Dalam: Goldsmith JP, Karotkin EH, penyunting. Assisted ventilation of the neonate. Edisi ke-3. Philadelphia: Saunders; 1996. h. 21-65.

12. Rab T. Agenda gawat darurat. Jilid 1. Bandung: Alumni; 1998. h. 206-21.

13. Wilson LM. Fungsi pernapasan normal. Dalam: Price SA, Wilson LM, penyunting. Patofisiologi proses-proses penyakit. Edisi ke-4. Jakarta: EGC; 1995. h. 645-60.

14. Hagedorn MI, Gardner SL, Abman SH. Respiratory disease. Dalam: Merenstein GB, Gardner SL, penyunting. Handbook of neonatal intensive care. Edisi ke- 3.USA: Mosby; 1993. h. 311-38

15. Spitzer AR. Mechanical ventilation. Dalam: Sitzer AR,penyunting. Intensive care of the fetus and neonate. USA: Mosby; 1996. h. 553-69.

16. Mammel MC, Baros SJ. High frequency ventilator. Dalam: Goldsmith JP, Karotkin EH, penyunting. Assisted ventilation of the neonate. Edisi ke- 3. Philadelphia: Saunders; 1996. h. 199-212.

17. Frantz ID. Mechanical ventilation. Dalam: Avery MA, Taeusch W, penyunting. Schaffer's diseases of the newborn. Edisi ke -5. Philadelphia: Saunders; 1984. h. 21720.

18. Kalton M, Cattran CB, Kent G. Oxygenation during high frequency ventilation compared with conventional mechanical ventilation in two models of lung injury. $\mathrm{J}$ Anesthesia and Analgesia 1982; 61:323-32.

19. Carlo WA, Chatburn RL, Martin RJ. Randomized trial of frequency jet ventilation versus convensional ventilation in respiratory distress syndrome. J Pediatr 1997; 110:275-81. 